\title{
A quantum chemistry description of carbon monoxide and water absorbates on single-crystal rhodium and platinum clusters
}

\author{
P. Paredes Olıvera, G. Estiu, E.A. Castro and A.J. Arvia * \\ Instituto de Investzgactones Fisicoquímicas Teóncas y Aplicadas (INIFTA), Facultad de Ciencias Exactas, Universidad Nacional de La Plata, \\ Sucursal 4, Castla de Correo 16, (1900) La Plata (Argentina)
}

(Received 13 January 1992, in revised form 31 August 1993)

\begin{abstract}
Fxtended Huckel molecular-orbital calculatıons of $\mathrm{CO}$ and $\mathrm{HO}$ adsorbed ensembles on single-crystal $\mathrm{Pt}$ and Rh clusters are presented The energy ranges related to the stability of adsorbed ensembles of the type $(\mathrm{Me})_{N}(\mathrm{CO})_{n}(\mathrm{OH})_{m}$, where $\mathrm{Me}$ stands for $\mathrm{Rh}(100), \mathrm{Rh}(111), \mathrm{Pt}(100)$ and $\mathrm{Pt}(111)$, were calculated for various coordindtion geometries and applied potential conditions $\mathrm{A}$ stability inversion potential was found for each ensemble A correlation was obtamed between the stability inversion potentials resulting from the different adsorbed ensembles and the potentials of the current peaks related to the voltammetric oxidation of $\mathrm{CO}$ adsorbates on $\mathrm{Pt}$ and $\mathrm{Rh}$ resulting from comparable potential perturbation conditions
\end{abstract}

\section{Introduction}

The chemisorption of $\mathrm{CO}$ on noble metals such as $\mathrm{Rh}$ and $\mathrm{Pt}$ in acid solutions is of particular interest with respect to $\mathrm{C} 1$ chemistry [1-5] because $\mathrm{CO}$ acts as a poison in the catalytic oxıdation of organic compounds such as methanol, formic acid and hydrocarbons by occupying active surface sites [6]

The electrocatalytıc properties of $\mathrm{Rh}$ and $\mathrm{Pt}$, which are known from the study of several electrochemical reactions, appear to be rather similar $[7,8]$ In the absence of specific metal complexing species, $\mathrm{Rh}$ and $\mathrm{Pt}$ behave as stable materials at all $\mathrm{pH}$ values in aqueous solutions, although the electrochemical oxidation of Rh takes place at a potential lower than that of Pt $[9,10]$ Data derived from ultrahigh vacuum (UHV) measurements $[11,12]$ for these two metals have shown that different metal-adsorbate and lateral adsorbateadsorbate interactions occur for those adsorbed intermediates which are involved in a number of catalytic oxidation reactions on $R h$ and Pt surfaces [13] A comprehensive understanding of the structure of $\mathrm{CO}$ adsorbates on $\mathrm{Pt}$ and $\mathrm{Rh}$ is required to improve the electrocatalytic performance of these metals [14-17]

\footnotetext{
* To whom correspondence should be addressed
}

Electrochemical [18-21] and UHV gas phase data [22-27] demonstrate that $\mathrm{CO}$ adsorbs on both $\mathrm{Rh}$ and Pt surfaces in linear and bridge forms, and the surface concentration ratio of these forms depends on $\theta_{\mathrm{CO}}$, the degree of metal surface covered by $\mathrm{CO}$, and the electronic characteristics of the metal surface, which are determined by the nature and the topography of the metal as well as the applied potential for electrochemıcal systems In these cases, for potentials lying in the range where $\mathrm{CO}$ electro-oxidation on $\mathrm{Pt}$ takes place, the $\mathrm{CO}$ bridge adsorbate configuration is almost absent [28]

Since the anodic strippıng voltammograms for $\mathrm{CO}$ adsorbates on $\mathrm{Rh}$ and $\mathrm{Pt}$ in aqueous clectrolyte solutions are very different (Figs 1 and 2) [18-20], it has been concluded that the adsorption energy difference between the bridge and linear forms of $\mathrm{CO}$ adsorbates on $\mathrm{Pt}$ is larger than that on $\mathrm{Rh}$ Accordingly, the interconversion between the two forms of $\mathrm{CO}$ on $\mathrm{Rh}$ will be easier than on $\mathrm{Pt}$, giving rise to a single $\mathrm{CO}$ anodic strippıng current peak for $\mathrm{Rh}(\mathrm{Fig} 2)$ instead of the current peak multiplicity found for $\mathrm{Pt}$ (Fig 1) [20]

Generally, $\mathrm{CO}$ adsurbate structures on noble metals in electrochemical systems have been described as coadsorbed complex ensembles [19,20], consisting of $\mathrm{CO}$ and $\mathrm{OH}$ species on well-defined $\mathrm{Pt}$ sites The presence of $\mathrm{OH}$ species results from the fast electro- 
oxidation of $\mathrm{H}_{2} \mathrm{O}$ which takes place at potentials slightly less positive than the $\mathrm{CO}$ adsorbate electrooxidation threshold potential Based upon of the existence of these adsorbed structures, a first molecular orbital explanation of the origin of the adsorbed $\mathrm{CO}$ electro-oxidation voltammetric current peaks in acid solution in the absence of anion specific adsorption on $\mathrm{Pt}(100)$ and $\mathrm{Pt}(111)$ [29], and on $\mathrm{Rh}(111)$ [30] has been advanced

Recent experimental [31-38] and theorelical [39-44] investigations of the mechanism of the $\mathrm{CO}$ electrooxidation reaction have confirmed that two main $\mathrm{CO}$ adsorbate coordination geometries are present on $\mathrm{Pt}$ and $\mathrm{Rh}$ surfaces However, recent experimental research has suggested different interpretations of the interaction of $\mathrm{CO}$ on noble metal surfaces, and a nucleation and growth mechanism, which implies the formation of $\mathrm{CO}$ islands on the metal substrate, has been proposed [45-50] Regardless of the model, it is generally accepted that the $\mathrm{CO}$ adsorbate oxıdizing agent is either $\mathrm{OH}$ or water molecules adjacent to the $\mathrm{CO}$ adsorption sites [45,51]
The first molecular orbital interpretation of adsorbed $\mathrm{CO}$ electro-oxidation on Pt surfaces was based on the existence of lateral interactions between $\mathrm{CO}$ and $\mathrm{OH}$ adsorbates at adjacent sites, disregarding the possibility of a nucleation and growth mechanism

This paper is the last in a series [31,32] devoted to a possible interpretation of the electro-oxidation of $\mathrm{CO}$ adsorbates formed on noble metals $(\mathrm{Me})$ on the basis of the stability of the $[\mathrm{Me}]_{N}(\mathrm{OH})_{n}(\mathrm{CO})_{m}$ ensembles formed on $\mathrm{Pt}(111), \mathrm{Pt}(100), \mathrm{Rh}(111)$ and $\mathrm{Rh}(100)$ as a function of the applied potential The calculation procedure describes the influence of the electronic characteristics of the metal surfaces on the stability of $\mathrm{CO}$ adsorbates on these noble metals Results indicate that the difference in the electrochemical electro-oxidation of adsorbed $\mathrm{CO}$ on $\mathrm{Pt}$ and $\mathrm{Rh}$ single crystals is due partly to the different adsorptive properties of the two metals with respect to $\mathrm{CO}$, and partly to the potential ranges of stability of $\mathrm{H}$ and $\mathrm{OH}$ adsorbed species, resulting from the electrochemical decomposition of water, on the metals It should be noted that the potential range where $\mathrm{CO}$ and $\mathrm{H}$ coadsorption takes
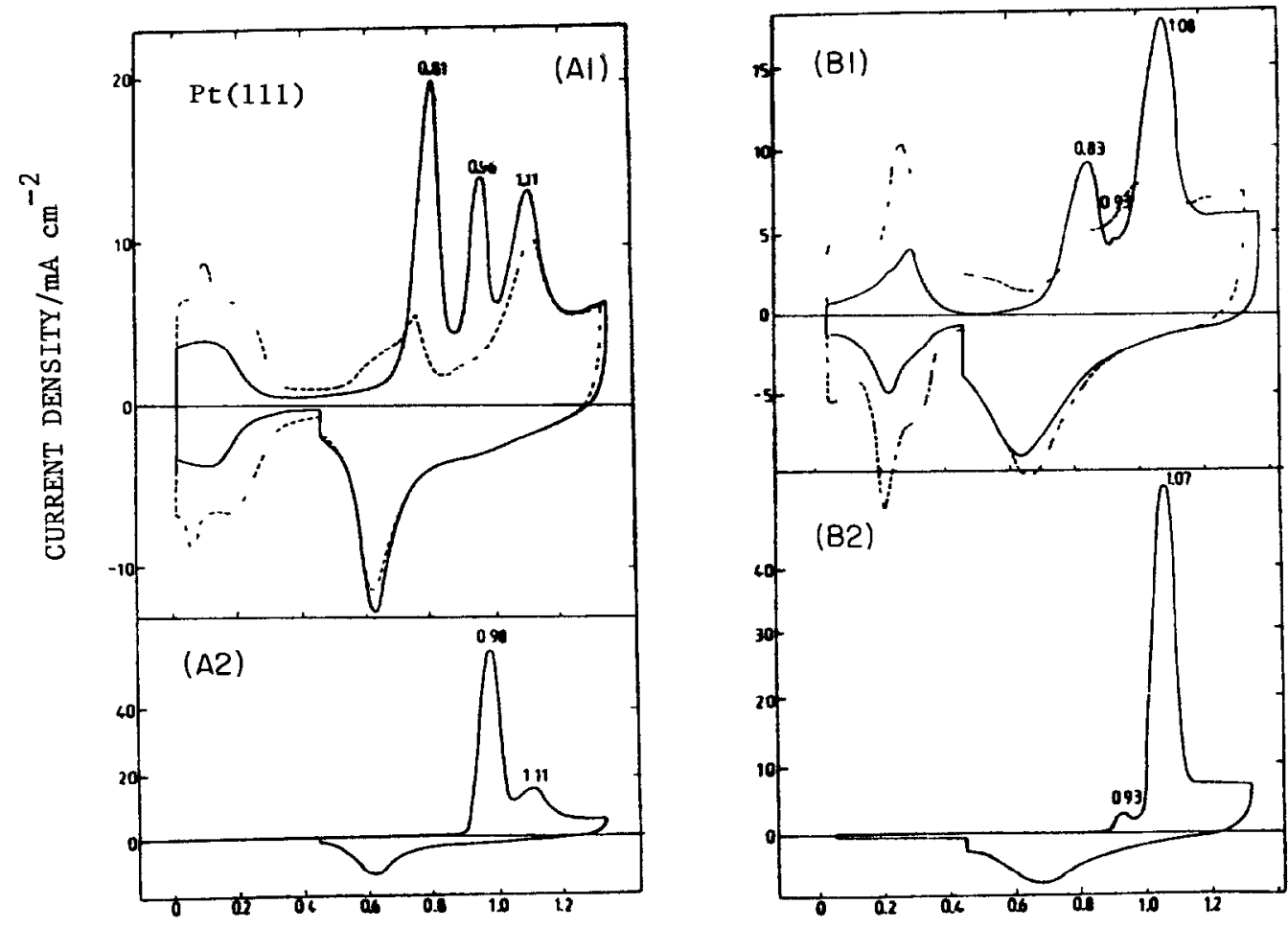

POTENTIAL/V vs. RHE

Fig 1 Voltammograms related to the electro-oxidation of $\mathrm{CO}$ adsorbates on (A) $\mathrm{Pt}(111)$ and (B) $\mathrm{Pt}(100)$ singie-crystal electrodes at $10 \mathrm{~V} \mathrm{~s} \mathrm{~s}^{-1}$ in CO-saturated $05 \mathrm{M} \mathrm{HClO}_{4}$ at a CO adsorption potential $E_{\text {ads }}$ of $045 \mathrm{~V} /(\mathrm{RHE})$ and different adsorption times $\tau_{\text {ads }}$ at $25^{\circ} \mathrm{C}(\mathrm{A} 1) \tau_{\text {ads }}=26 \mathrm{~s}$ (full curve), and blank (broken curve), (A2) $\tau_{\text {ads }}=25 \mathrm{~s}$, (B1) $\tau_{\text {ads }}=28 \mathrm{~s}$ (full curve) and blank (broken curve), (B2) $\tau_{\text {ads }}=20 \mathrm{~s}$ Data taken from ref 2 with permission of Elsevicr Scicnce Publishers 
place on Rh is larger than that on Pt [20] We understand that the conclusions derived from molecular orbital calculations are compatible with the nucleation and growth model, as the proposed $\mathrm{CO}$ adsorption geometries are valid for the first layer of the adsorbed nucleus
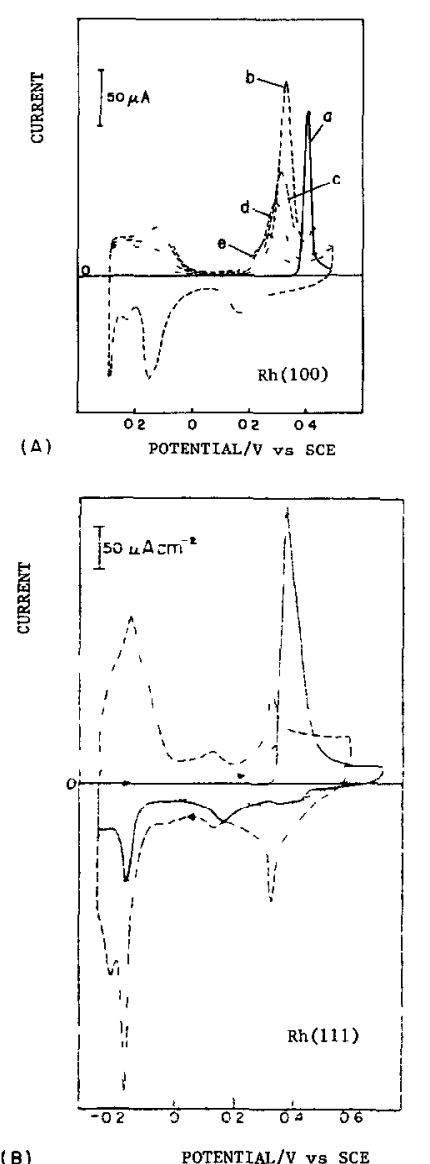

(B)

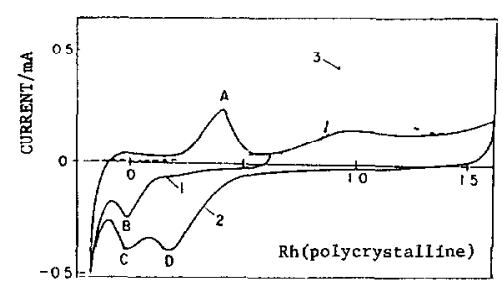

(c)

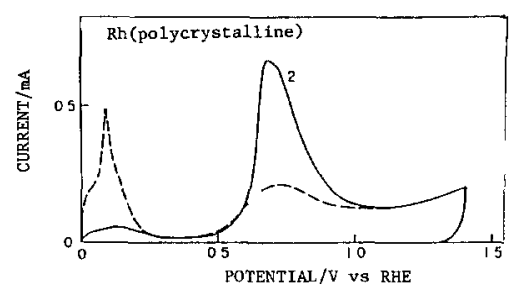

(D)
This work covers the following topics The calculatıon procedure and experımental literature data are reviewed in Sections 2 and 3 The dependence of the possible $\mathrm{CO}$ adsorbate configurations on the electronic characteristics of the metal surface is discussed in Section 4 Finally, in Sections 5 and 6 a correlation is attempted between the stability inversion potentials resulting from the different adsorbed ensembles, and the anodic stripping potentials of $\mathrm{CO}$ adsorbates on $\mathrm{Pt}$ and $\mathrm{Rh}$

\section{Outline of the calculation procedure}

The value of the energy $E$ related to chemical bond formation is given by the sum of two energy components $E_{\mathrm{R}}$ and $E_{\mathrm{MO}} \quad E_{\mathrm{R}}$ is a pairwisc atom-atom repulsive energy term and $E_{\mathrm{MO}}$ is an attractive energy term due to electron delocalization and bond formation Following the procedure of Anderson and coworkers [52,53], this energy has been approximated as a sum of one-electron molecular orbital energies obtained by diagonalizing a Hamiltonian similar in form to the extended Huckel Hamilonian

The method can be described briefly as follows The energy matrix elements of the attractive energy component were calculated from the equations [52]

$$
\begin{aligned}
& H_{t \imath}^{a a}=-(\mathrm{VSIP})_{\imath}{ }^{a} \\
& H_{\imath \jmath}^{a a}=0 \\
& H_{\imath \jmath}^{a b}=1125\left(H_{\imath t}^{a a}+H_{j}^{b b}\right) S_{\imath \jmath}^{a b} \exp (-013 R)
\end{aligned}
$$

where the $\iota$ run over all orbitals and the $a$ run over all atoms, VSIP denotes the valence state ionization potential, $S_{t j}^{a b}$ is the overlap integral between orbital $\imath$ on centre $a$ and orbital $J$ on centre $b$, and $R$ is the internuclear distance between centres $a$ and $b$ The values of $S_{t j}^{a b}$ were calculated using Slater-type valence orbitals The exponents of the Slater orbitals were taken from the literature [54]

Core-core repulsive energy values $E_{\mathrm{R}}$ were calculated as pairwise additive in the way proposed by Anders et al [55]

Fig 2 Voltammograms related to the electro-oxidation of $\mathrm{CO}$ adsorbates at $005 \mathrm{~V} \mathrm{~s}^{-1}$ on different $\mathrm{Rh}$ electrodes (A) $\mathrm{Rh}(100)$ in $01 \mathrm{M}$ $\mathrm{HClO}_{4}$ (a) $\theta_{\mathrm{CO}}=077$, (b) $\theta_{\mathrm{CO}}=045$, (c) $\theta_{\mathrm{CO}}=03$, (d) $\theta_{\mathrm{CO}}=02$, (e) $\theta_{\mathrm{CO}}=01$ The current scale voltammogram (a) is fourfold compressed (B) $\mathrm{Rh}(111)$ in $01 \mathrm{M} \mathrm{HClO}_{4} E_{\mathrm{ads}}=-025 \mathrm{~V}$ (full curve), blank (dotted curve) The broken curve corresponds to the blank with a current scale magnified 25 times (C) Polycrystalline Rh in 02 $\mathrm{M} \mathrm{K}_{2} \mathrm{SO}_{4}$ The broken curve corresponds to the blank (D) Polycrystalline $\mathrm{Rh}$ in $05 \mathrm{M} \mathrm{H}_{2} \mathrm{SO}_{4}$ in the absence (dashed line) and presence (solid line) of an adsorbed CO monolayer Data from refs 21, 29 and 30 by permission of Elsevier Science Publıshers and The American Chemical Society 
The binding energy $(\mathrm{BE})$ between a complex adsorbate such as $(\mathrm{CO})_{n}(\mathrm{OH})_{m}$ consistıng of an ensemble of $n \mathrm{CO}$ and $m \mathrm{OH}$ species on a substrate metal site $[\mathrm{Me}]_{N}$ formed by $N$ metal atoms, is defined as follows

$$
\mathrm{BE}=E_{[\mathrm{Me}]_{N}(\mathrm{CO})_{n}(\mathrm{OH})_{m}} n E_{(\mathrm{CO})}-m E_{(\mathrm{OH})}-E_{[\mathrm{Me}]_{N}}
$$

where the $E$ denote the energies of the different ensembles

To reproduce the work function modification due to adsorption, the initial values of VSIPs given in refs 56 and 57 were adjusted until the charge transfer at the cquilibrium distance in the heteronuclear diatomic bond was close to that predicted by the electronegativity difference in Paulıng's ionicity relatıonshıp [58]

The charge transfer reaction

$$
[\mathrm{Me}]+\mathrm{H}_{2} \mathrm{O}=[\mathrm{Me}](\mathrm{OH})+\mathrm{H}^{+}+\mathrm{c}^{-}
$$

involving the reversible electroadsorption of the water molecule on the metal defines the equilıbrium electrode potential The charge transfer induced by the $\mathrm{O}$ atom is larger than that induced by the $\mathrm{C}$ atom bonded to the metal Consequently, the VSIPs of this system were taken as a reference for simulating the electric potentral applied to the electrochemical interface A positıve applied electric potentıal shifts the Fermı level of the metal downwards in the energy scale and vice versa Thus these changes were simulated by either decreasing or increasing the VSIPs of the metal from the reference values associated with the equilibrium electrode potential defined by eqn (5) The values of VSIPs and Slater orbital exponents employed in the calculations are given in Tablc 1

It should be noted that a $1 \mathrm{~V}$ shift in the applied electric potential does not necessarily correspond to a $1 \mathrm{eV}$ shift in VSIP In earlier work it was found that a correlation $g \approx 03 \mathrm{eV} \mathrm{V}^{-1}$ allowed a reasonable description of the energy range of stable $\mathrm{CO}$ adsorbate structures on $\operatorname{Pt}(111)(g=032)$ [31] and $\operatorname{Rh}(111)(g=$
0 30) [32] This value of $g$ could be justıfied from ESCA measurements at the $\mathrm{Au}(100)+05 \mathrm{M} \mathrm{NaF}$ system $[59,60]$ For this system a $10 \mathrm{~V}$ shift in the energy of bulk states was related to a $03 \mathrm{eV}$ shift in surface state energy $[59,60]$ The shift in Fermı energy level with the applied electric potential differs appreciably for various metal |electrolyte solution interfaces, as is expected since the characteristics of the correlation are determined by both surface and bulk state energies, which in turn exhibit specific responses to the applied electric potential For example, in contrast with $g=03$ $\mathrm{eV} \mathrm{V}^{-1}$ for $\mathrm{Au}(100)+05 \mathrm{M} \mathrm{NaF}$, the value of $g$ for the $\mathrm{Ag}(110)+05 \mathrm{M} \mathrm{NaF}$ system ranges from 3 to 4 $\mathrm{eV} \mathrm{V}^{-1}$ [61] In the case we are studyıng, the electronıc structure of the surface, defined by the nature and topology of the metal, has an influence on the $g$ value, as shown in Table 2

Clusters $[\mathrm{Me}(111)]_{22}$ and $[\mathrm{Me}(100)]_{25}$ with $\mathrm{d}$ bands filled with at least one electron per orbital were used to model the single-crystal metal surfaces (Fig 3) The clusters were constructcd gcometrically from the $\mathbf{R h}-$ $\mathrm{Rh}$ and $\mathrm{Pt}-\mathrm{Pt}$ closest approach distances $(02687 \mathrm{~nm}$ and $02770 \mathrm{~nm}$ respectively) The smallest cluster dimension compatible with the minimum influence of border effects was used to model the adsorption systems Accordingly, cooperative interactions between adsorbates on the central four-atom region of the cluster were considered (Figs 4 and 5)

The $\mathrm{Me}-\mathrm{CO}$ and $\mathrm{Me}-\mathrm{OH}$ adsorption bond lengths were calculated from the minımum of binding energy versus Me-adsorbate distance curves A linear configuration perpendicular to the metal surface was considered for both $\mathrm{CO}$ and $\mathrm{OH}$ in the coadsorbed systems on the basis of the adsorption geometries of the species separately $[19,31]$ The $\mathrm{C}-\mathrm{O}$ and $\mathrm{O}-\mathrm{H}$ interatomic distances were fixed at $0116 \mathrm{~nm}$ and $0100 \mathrm{~nm}$ respectively The $\mathrm{OH}$ species adsorbed at $0195 \mathrm{~nm}$ from the $\mathrm{Rh}(111)$ surface and $020 \mathrm{~nm}$ from the $\mathrm{Pt}(111)$ surface,

TABLE 1 Parameters used in the calculations principal quantum number $n$ for $\mathrm{s}, \mathrm{p}$ and $\mathrm{d}$ orbitals, orbital exponent $\xi$, ionization potentıal VSIP

\begin{tabular}{|c|c|c|c|c|c|c|c|c|c|c|c|c|c|}
\hline \multirow[t]{2}{*}{ Atom } & & \multicolumn{3}{|c|}{ s orbital } & \multicolumn{3}{|c|}{ p orbital } & \multicolumn{6}{|c|}{ d orbital } \\
\hline & & $n$ & $\xi$ & VSIP & $\bar{n}$ & $\xi$ & VSIP & $n$ & $\xi_{1}$ & VSIP & $C_{1}$ & $C_{2}$ & $\xi_{2}$ \\
\hline \multirow[t]{2}{*}{$\mathrm{O}$} & (A) & 2 & 1946 & -2698 & 2 & 1927 & -1212 & & & & & & \\
\hline & (B) & 2 & 2146 & -2698 & 2 & 2127 & -1212 & & & & & & \\
\hline $\mathbf{H}$ & (A) & 1 & 1000 & -1210 & & & & & & & & & \\
\hline $\mathrm{C}$ & (B) & 2 & 1658 & -1850 & 2 & 1618 & -9760 & & & & & & \\
\hline $\mathrm{Rh}$ & (C) & 5 & 2135 & -9670 & 5 & 2100 & -6314 & 4 & 4290 & -1177 & 05807 & 5686 & 1970 \\
\hline $\mathrm{Pt}$ & (C) & 6 & 2850 & -1099 & 6 & 2550 & -6955 & 5 & 6310 & -1159 & 06640 & 05779 & 2410 \\
\hline
\end{tabular}
and coefficients $C_{1}$ and $C_{2}$ for d orbitals

(A) Atom in $\mathrm{H}_{2} \mathrm{O}$ molecule

(B) Atom in $\mathrm{CO}$ molecule

(C) $\mathrm{Me}$ in either $[\mathrm{Me}(100)]_{25}\left(\mathrm{H}_{2} \mathrm{O}\right)(\mathrm{CO})$ or $[\mathrm{Me}(111)]_{22}\left(\mathrm{H}_{2} \mathrm{O}\right)(\mathrm{CO})$ ensembles 
TABLE 2 Correlation between SIP values of different $\mathrm{CO}$ adsorbates on $\mathrm{Me}(111)$ or $\mathrm{Me}(100)(\mathrm{Me}=\mathrm{Pt}(\mathrm{A})$ or $\mathrm{Rh}(\mathrm{B}))$ and the potentials of the $\mathrm{CO}$ electro-oxidation voltammetric peaks recorded at constant potential sweep $v$

\begin{tabular}{|c|c|c|c|c|}
\hline & $\begin{array}{l}\text { SIP } \\
\text { (calc) } \\
/ \mathrm{eV}\end{array}$ & $g^{\mathrm{a}} / \mathrm{eV} \mathrm{V}^{-1}$ & $\begin{array}{l}\text { EOP } \\
\text { (calc) } \\
/ \mathrm{V}\end{array}$ & $\begin{array}{l}\text { EOP } \\
(\exp ) \\
/ V\end{array}$ \\
\hline $\begin{array}{l}M e=P t \\
\text { Pt(111)CO } \\
\text { Figs } 41(\mathrm{a}), 41(\mathrm{~d})\end{array}$ & 025 & 032 & 078 & 081 \\
\hline $\begin{array}{l}\text { Figs } 41(b), 41(e) \\
\text { Fis }\end{array}$ & 030 & 032 & 094 & 096 \\
\hline $\begin{array}{l}\text { Pt(111)CO } \\
\text { Figs } 4 \text { 1(c), } 4 \text { 1(f) }\end{array}$ & 035 & 032 & 109 & 111 \\
\hline $\begin{array}{l}\mathrm{Pt}(111) \mathrm{CO}^{\mathrm{B}} \\
\text { Fig } 42(\mathrm{a}), 42(\mathrm{~b})\end{array}$ & 039 & 032 & 121 & - \\
\hline $\begin{array}{l}\mathrm{Pt}(100) \mathrm{CO}^{\mathrm{T}} \\
\text { Fig } 51(\mathrm{~b}), 51(\mathrm{f})\end{array}$ & 023 & 027 & 085 & 083 \\
\hline $\begin{array}{l}\mathrm{Pt}(100) \mathrm{CO}^{\mathrm{T}} \\
\text { Fig } 51(\mathrm{c}), 51(\mathrm{f})\end{array}$ & 025 & 027 & 093 & 093 \\
\hline $\begin{array}{l}\mathrm{Pt}(100) \mathrm{CO}^{\mathrm{T}} \\
\text { Fig } 51(\mathrm{~d}), 51(\mathrm{~g})\end{array}$ & 031 & 027 & 114 & 108 \\
\hline $\begin{array}{l}M e=R h \\
\text { Rh(111)CO } \\
\text { Fig } 41(\mathrm{a}), 41(\mathrm{~d})\end{array}$ & 014 & 029 & 048 & 047 \\
\hline $\begin{array}{l}\mathrm{Rh}(111) \mathrm{CO}^{\mathrm{T}} \\
\text { Flg } 41(\mathrm{~b}), 41(\mathrm{e})\end{array}$ & 022 & 029 & 076 & 075 \\
\hline $\begin{array}{l}\mathrm{Rh}(111) \mathrm{CO}^{\mathrm{H}} \\
\text { Fig } 43(\mathrm{a}), 43(\mathrm{~b})\end{array}$ & 048 & 029 & 165 & 162 \\
\hline $\begin{array}{l}\mathrm{Rh}(100) \mathrm{CO}^{\mathrm{T}} \\
\text { Flg } 51(\mathrm{a}), 51(\mathrm{e})\end{array}$ & 024 & 031 & 077 & 075 \\
\hline $\begin{array}{l}\mathrm{Rh}(100) \mathrm{CO}^{\mathrm{T}} \\
\text { Fig } 51(\mathrm{~b}), 51(\mathrm{f})\end{array}$ & 030 & 031 & 097 & 095 \\
\hline $\begin{array}{l}\mathrm{Rh}(100) \mathrm{CO}^{\mathrm{T}} \\
\text { Fig } 51(\mathrm{c}), 51(\mathrm{f})\end{array}$ & 043 & 031 & 138 & - \\
\hline $\begin{array}{l}\text { Rh(100)CO } \\
\text { Fig } 51(d), 51(g)\end{array}$ & 044 & 031 & 141 & - \\
\hline $\begin{array}{l}\mathrm{Rh}(100) \mathrm{CO}^{\mathrm{B}} \\
\text { Fig } 52(\mathrm{a}), 52(\mathrm{~b})\end{array}$ & 029 & 031 & 094 & 095 \\
\hline
\end{tabular}

The values indicate the probable adsorbate involved at different electro-oxidation potentials Calculated (calc) and experımental (exp) EOP values are given The relation between EOP (calc), SIP (calc) and $g$, as well as the definition of $g$, are given in the text

a $v=10 \mathrm{~V} \mathrm{~s}^{-1}$ for $\mathrm{Pt}$ and $v=005 \mathrm{~V} \mathrm{~s}^{-1}$ for $\mathrm{Rh}$

whereas in the presence of adsorbed $\mathrm{OH}$ the $\mathrm{CO}$ molecule is stabilized at $0224 \mathrm{~nm}$ from the $\mathrm{Rh}(111)$ surface and $0213 \mathrm{~nm}$ from the $\mathrm{Pt}(111)$ surface

\section{Adsorbed CO voltammetric electro-oxıdation on Rh and Pt: summary of the experimental data}

The electrochemical oxıdation of $\mathrm{CO}$ adsorbates in acid electrolytes has been investigated on $\mathrm{Rh}$ [21] and more extensively on $\mathrm{Pt}$ single crystals and $\mathrm{Pt}$ polycrystalline electrodes $[1,2,18,19]$ for different values of $\theta_{\mathrm{CO}}$ Recently, absolute surface IR spectra for $\mathrm{CO}$ on $\mathrm{Rh}(100)$ and $\mathrm{Rh}(111)[29,30]$ and on $\mathrm{Pt}(111)$ and $\mathrm{Pt}(100)$
[37] in acid solution have also becn reported as a function of $\theta_{\mathrm{CO}}$ and the electrode potential $V$

The electro-oxidation of adsorbed $\mathrm{CO}$ on Pt and $\mathrm{Rh}$ (Figs 1 and 2) in aqueous solution behaves as a typical irreversible electrochemical process The reaction taking place on these metals exhibits some common features, namely the multiplicity and position of the corresponding voltammetric peaks depend strongly on $\theta_{\mathrm{CO}}$, the crystal face of the metal and the electrolyte composition including $\mathrm{pH}$ Thus, for $\theta_{\mathrm{CO}} \approx 05$, two CO electro-oxıdation peaks were found for $\operatorname{Pt}(100)$ and $\operatorname{Pt}(111)$ In acid media In contrast, for $\theta_{\mathrm{CO}} \approx 1$, a single sharp anodic voltammetric peak located at a high positive potential was observed

However, on polycrystalline $\mathrm{Rh}$ with $\theta_{\mathrm{CO}} \approx 1$, the electro-oxıdation of adsorbed $\mathrm{CO}$ in acid exhıbits a single, although somewhat distorted, anodic peak (Fig 2A) probably involving a complex structure The characteristics of this peak agree with the pseudo-derivative shape of the corresponding electromodulated IR spectral (EMIRS) band [30] Furthermore, the features of the anodic peak depend on whether the reaction takes place on $\mathrm{Rh}(100)$ or $\mathrm{Rh}(111)$ (Fig 2B) In the former case, the shift of the peak potentıal to lower values as $\theta_{\mathrm{CO}}$ is decreased from 077 to 01 suggested the existence of two distinguishable types of $\mathrm{CO}$ adsorbates on Rh in acids

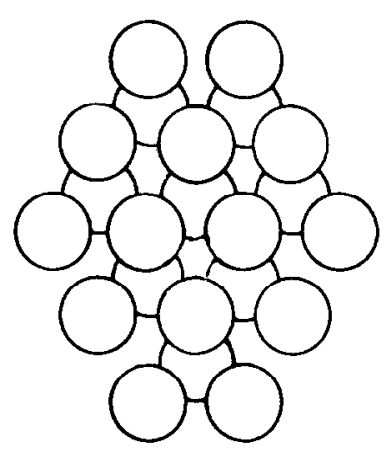

(a)

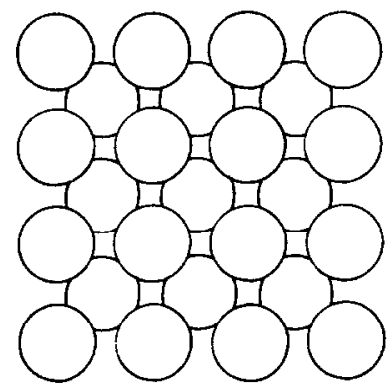

(b)

Fig 3 Cluster models for the different Me surface sites (a) Me(111), (b) $\mathrm{Me}(100) \mathrm{Mc}=\mathrm{Rh}, \mathrm{Pt}$ 
The existence of different $\mathrm{CO}$ adsorption bonds has been concluded from UHV data for Rh/CO(gas) and $\mathrm{Pt} / \mathrm{CO}$ (gas) systems [22-27] The latter were also used to describe the electrochemical behaviour of $\mathrm{CO}$ Thus the anodic peak for Pt at low potentials was associated with bridge-bonded (bicoordinated) $\mathrm{CO}$, whereas the peak at high potentials was attributed to linearly bonded $\mathrm{CO}[2,3]$ The origin of the single desorption voltammetric peak obtained on polycrystallıne $\mathrm{Rh}$ [21] was assigned exclusively to the presence of linearly
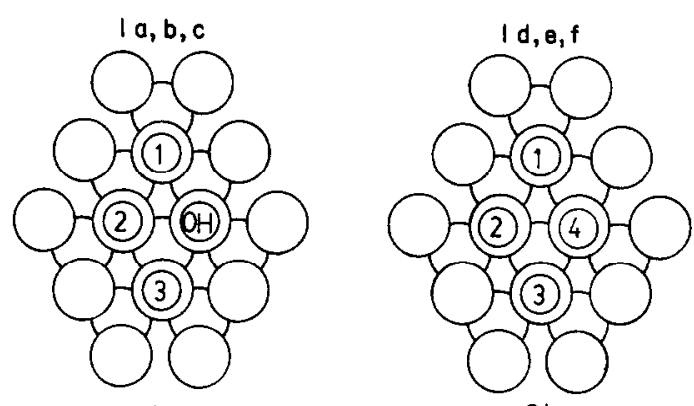

20

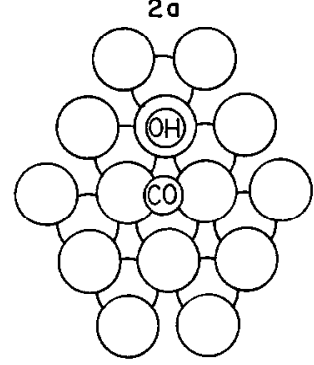

$2 b$

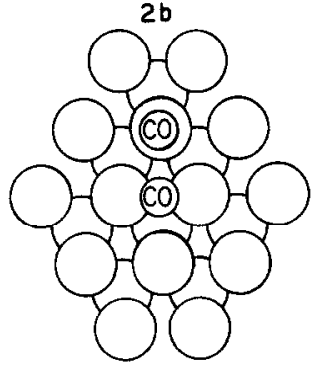

30
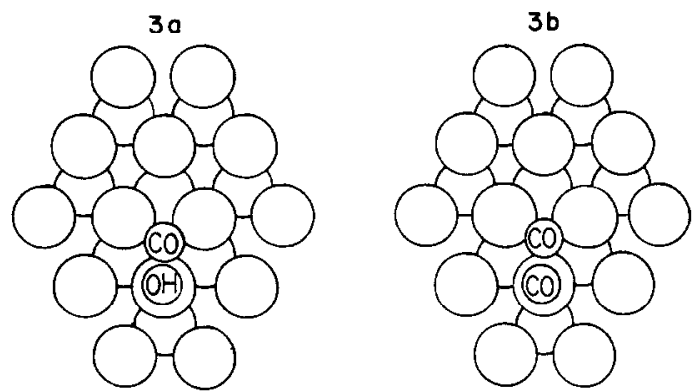

Local structures defined around the central atom of $[\mathrm{Me}(111)]_{22}$

$\begin{array}{lllll} & \text { Site 1 } & \text { Site 2 } & \text { Site 3 } & \text { Site } 4 \\ \text { (a) } & \mathrm{CO} & \text { Empty } & \text { Empty } & - \\ \text { (b) } & \mathrm{CO} & \mathrm{CO} & \text { Empty } & - \\ \text { (c) } & \mathrm{CO} & \mathrm{CO} & \mathrm{CO} & - \\ \text { (d) } & \mathrm{CO} & \text { Empty } & \text { Empty } & \mathrm{CO} \\ \text { (e) } & \mathrm{CO} & \mathrm{CO} & \text { Empty } & \mathrm{CO} \\ \text { (f) } & \mathrm{CO} & \mathrm{CO} & \mathrm{CO} & \mathrm{CO}\end{array}$

Fig 4 Local structures involving the central atoms of the cluster The energies of the various configurations were compared as described in the text in order to define the stability inversion potential (SIP) on $\mathrm{Me}(111)$
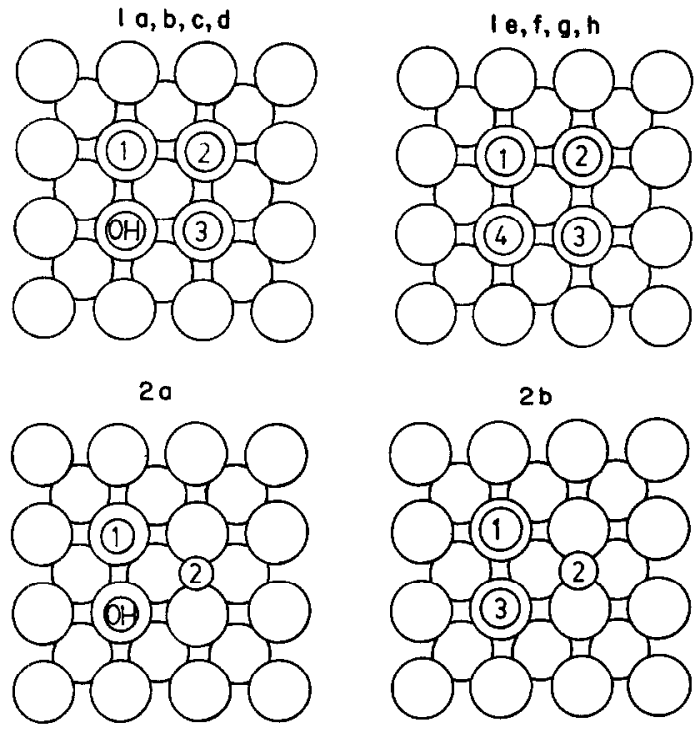

Local structures defined on the central atom of $[\mathrm{Me}(100)]_{25}$

$\begin{array}{llll} & \text { Site 1 } & \text { Site 2 } & \text { Site 3 } \\ \text { (a) } & \mathrm{CO} & \mathrm{CO} & - \\ \text { (b) } & \mathrm{CO} & \mathrm{CO} & \mathrm{CO}\end{array}$

Fig 5 Local structures involving the central atoms of the cluster The energies of the various configurations were compared as described in the text in order to define the SIP on Me(100)

bonded $\mathrm{CO}$ produced by the interconversion from facile bildge to linear adsorbate at the Rh surface However, this explanation disagrees with gas phase spectroscopic data which suggest that only linearly bonded $\mathrm{CO}$ is piesent on $\mathrm{Rh}$ for $\boldsymbol{\theta}_{\mathrm{CO}} \Rightarrow 1$ The oxidative desorption of $\mathrm{CO}$ adsorbates from both $\mathrm{Rh}$ and $\mathrm{Pt}$ has been explained in terms of a mechanism of lateral interactions between $\mathrm{CO}$ and oxygenated intermediates adsorbed on the metal surface $[19,20,31,32]$ However, the different types of electrochemical behaviour of $\mathrm{Rh}$ and $\mathrm{Pt}$, which are manifested even in the absence of adsorbed $\mathrm{CO}$, were not properly considered in dealing with the differences in the oxidative desorption of $\mathrm{CO}$ adsorbates on those metals It should be noted that the $\mathrm{H}$ and $\mathrm{O}$ adatom electroadsorption potential ranges on $\mathrm{Rh}$ in acid are narrower than those on Pt Correspondingly, the potential range for $\mathrm{CO}$ and $\mathrm{H}$ coadsorption is greater on $\mathrm{Rh}$ than on Pt [9], and the overlap of the potential ranges of $\mathrm{O}$ adatoms for $\mathrm{Rh}$ becomes much larger than for $\mathrm{Pt}$ Hence the $\mathrm{O}$ electroadsorption on $\mathrm{Rh}$ should be strongly inhibited by the presence of $\mathrm{CO}$ [20], and the electrodesorption of $\mathrm{CO}$ from Rh should depend more strongly on the type of $(\mathrm{OH})(\mathrm{CO})$ lateral interactions than for $\mathrm{Pt}$ The shift in the potential of the anodic peak from $075 \mathrm{~V}$ in acid to $095 \mathrm{~V}$ in neutral solution (Fig 2C) on polycrystallıne $\mathrm{Rh}$ sug- 
gests that the $(\mathrm{OH})(\mathrm{CO})$ lateral interactions become largely influenced by the solution composition $[29,62]$

\section{Dependence of the probable $\mathrm{CO}$ adsorbate configu- rations on the electronic characteristics of the metal surface}

The possible structures of $\mathrm{CO}$ adsorbates on noble metals has been extensively investigated through the $\mathrm{C}-\mathrm{O}$ stretching frequency, which characterizes the $\mathrm{CO} /$ metal surface bonding $[28,36,38,46-50]$ Recently, it was found that the bridge to linear $\mathrm{CO}$-adsorbate interconversion on $\mathrm{Pt}$ and $\mathrm{Rh}$ cannot be related to simularities in binding energy From the dependence of the spectral frequency on the electric potential measured in situ using IRRAS EMIRS technıques, it seems more reasonable to assign the $\mathrm{CO}$-adsorbate electrodesorption peak multiplicity on $\mathrm{Pt}$ and $\mathrm{Rh}$ to potential-1nduced structural effects $[28,63]$

The spectral frequency shift was quantitatively interpreted by the application of semi-empirical MO-based ASED calculations [53,64,65] Accordingly, the increase in the $\mathrm{CO}$ stretching frequency due to the displacement of $\mathrm{CO}$ adsorbates from multıple to single adsorption sites as the potential is positively shifted was explained on the basis of Blyholder's model for $\mathrm{CO}$ molecules through a higher stabilization of the $5 \sigma$ donation to the lower-level metal valence band [53,6466] Interactions of both $\sigma$ and $\pi$ type are known to contribute to the Me- $\mathrm{CO}$ bond formation [3943,63,66] According to ab-initio calculations, $\sigma$-type interactions are mainly repulsive (Paulı repulsion) $[43,44,63,66]$ The Me charge in $\sigma$-symmetry orbitals hybridizes and polarizes away from $\mathrm{CO}$ to reduce the $\mathrm{Me}-5 \sigma$ CO overlap and hence to reduce repulsion Otherwisc, the $\pi$-typc interactions are bonding and are the most important in the stabilization of the $\mathrm{Me}-\mathrm{CO}$ bond Ab-initio $[43,44,63,66]$ density functional $[41,42]$ and semi-empirical [31,32,39] calculations, together with in-situ IR spectroscopy data, demonstrate that linearly coordinated $\mathrm{CO}$ adsorbates are present on both $\mathrm{Pt}$ and $\mathrm{Rh}$ in the potentral range where electrodesorption of $\mathrm{CO}$ adsorbates takes place Therefore the conclusions derived from the present approach (Fig 6) agree with those reported previously

\section{Possible structures involved in the $\mathrm{CO}$ electro-oxida- tion process}

Provided that lateral interactions between adsorbed species are involved in the stability of $\mathrm{CO}$ adsorbates at any value of $\theta_{\mathrm{CO}}$, the electrochemical desorption of $\mathrm{CO}$ adsorbates in the aqueous environment should
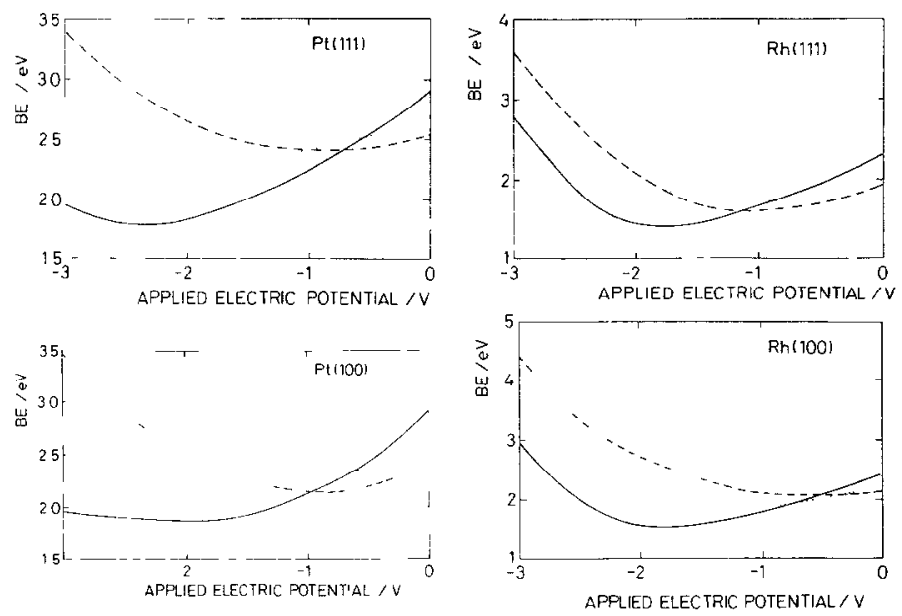

Fig 6 Binding energy (BE) shifts for $\mathrm{CO}$ adsorbed on different surfaces sites as a function of the applied potential (positive charging)

occur for a certain potential value at which the stability range of $(\mathrm{OH})(\mathrm{CO})$ coadsorbates is exceeded The threshold potentials related to the electro-oxidation of $\mathrm{CO}$ adsorbates have been semi-empirically associated with the stability limits of different adsorbate ensembles represented as $\left[\mathrm{Me}_{N}(\mathrm{CO})_{n}(\mathrm{OH})_{m}(N=22,25\right.$, $n=1,2,3, m=1, \mathrm{Me}=\mathrm{Pt}, \mathrm{Rh})$ At certain applied potentials which depend on the values of $m$ and $n$, a new $[\mathrm{Me}]_{N}(\mathrm{CO})_{n+m}$ ensemble is formed by displacement of the $\left(\mathrm{CO}_{n}\right)(\mathrm{OH})_{m}$ by $(\mathrm{CO})_{m+n}$ in the adsorption site In terms of the nucleation and growth model, $\mathrm{CO}$ adsorbates may belong to either second- or higher-order layers of islands, and in this way the stretching frequency is maintained unshifted through the occupation of sites of the same coordination geometry According to energy calculations, the formation of the $[\mathrm{Me}]_{N}(\mathrm{CO})_{m+n}$ ensemble seems to be more likely than the formation of coadsorbed structures such as $\mathrm{CO} \mathrm{OH}, \mathrm{CO} \mathrm{H}_{2} \mathrm{O}$ or $\mathrm{COH} \mathrm{OH}[32]$

Spectroscopic data of the $\mathrm{Me}+\mathrm{CO}$ (gas) system were considered in order to establish the most stable initial adsorbate structure for the different values of $\theta_{\mathrm{CO}}$, and to determine how these structures are modified when a positive potential is applied (Figs 7-11) The stability calculations of those structures which were built up on the central four-metal-atom region of each cluster to minımize cluster border effects provide information about the possible local interactions for different values of $\theta_{\mathrm{CO}}$ (Figs 4 and 5)

At low $\theta_{\mathrm{CO}}$ values a $(\sqrt{3} \times \sqrt{3}) R 30^{\circ}$ LEED CO adsorbate pattern is produced on both $\mathrm{Rh}(111)$ and Pt(111) in contact with CO gas through the occupancy of top sites [22,24,25,29,37] (Fig 7), giving rise to the nearest-neighbour interactions depicted in Fig 4 1(a) At intermediate $\theta_{\mathrm{CO}}$ values either a $c(2 \times 2)$ LEED 


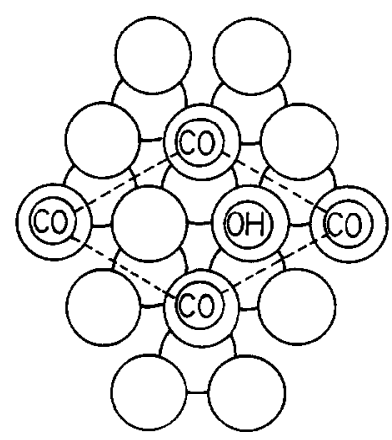

Fig $7(\sqrt{3} \times \sqrt{3}) R 30^{\circ}$ LEED pattern correspondıng to $\mathrm{CO}$ adsorbed on $\mathrm{Me}(111)$ for $\theta_{\mathrm{CO}}=033$ The possible $\mathrm{OH}$ adsorption site is also included The structure of the adsorbed layer remains at positive potential

pattern on $\mathrm{Rh}(111)$ or a $c(4 \times 2)$ LEED pattern on Pt(111), implyıng the simultaneous occupancy of either top and hollow sites or top and bridge sites of the surface respectively, is produced (Fig 8) Different local interactions obtaincd by changing the adsorption geometry of the $\mathrm{CO}$ molecule by a positive applied potential are illustrated in Fig 4 1(a)-4 1(c) Likewise, multibonded $\mathrm{CO}$ species would result from the interactions depicted in Figs 42 and 43 for Pt(111) and $\mathrm{Rh}(111)$ respectively However, although the presence of multıbonded $\mathrm{CO}$ species is rather unlıkely on un-
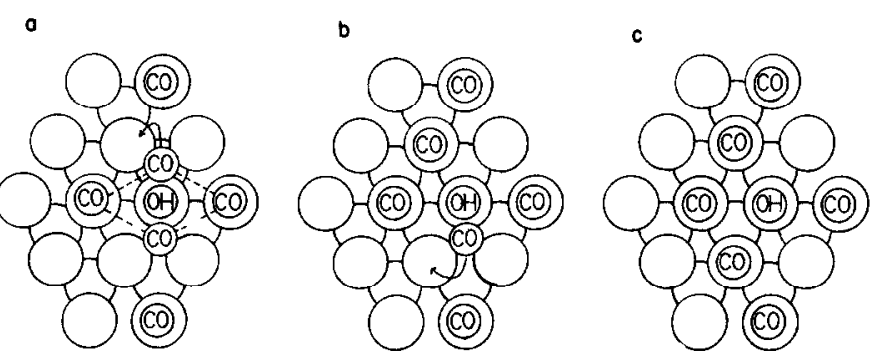

(A) a
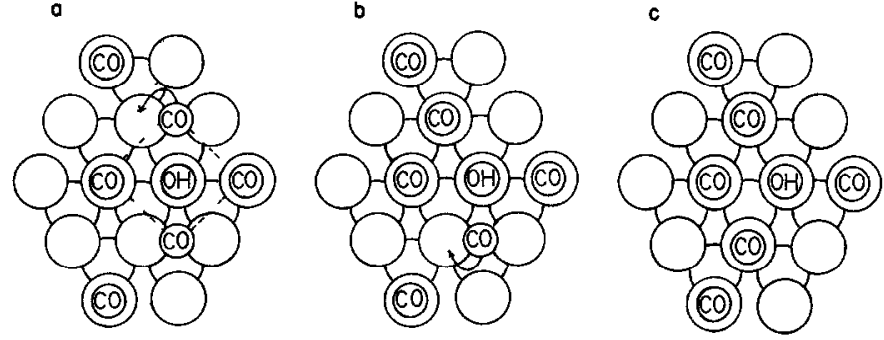

Fig 8 (A) (a) Adsorbed structure derived from the $c(2 \times 2)$ LEED pattern of $\mathrm{CO}$ adsorbed on $\mathrm{Rh}(111)$ (uncharged surface) for $\theta_{\mathrm{CO}}=$ 05 , the $\mathrm{OH}$ adsorption site is also included, (b), (c) adsorbed structures resulting for a positive potential to the initial $c(2 \times 2)$ structure (B) (a) Adsorbed structure as derived from the $c(4 \times 2)$ LEED pattern of $\mathrm{CO}$ adsorbed on $\mathrm{Pt}(111)$, (b), (c) adsorbed structures obtained by applying a positive potential to the initial $c(4 \times 2)$ structure
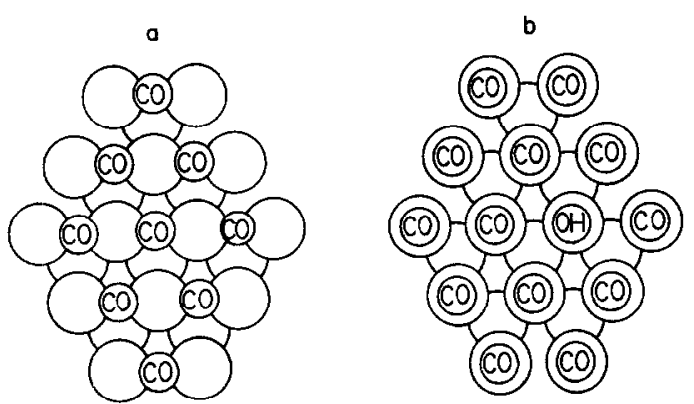

Fig 9 (a) $\mathrm{CO}$ adsorbate structures on $\mathrm{Me}(111)$ for $\theta_{\mathrm{CO}}=1$, (b) adsorbed structures obtained for a positive potential applied to the initial structure $A$ local vacancy is necessary for $\mathrm{OH}$ adsorption

charged metals, the stability of these species has also been evaluated

Unfortunately, at present there are no conclusive data related to the structure of $\mathrm{CO}$ adsorbates for $\theta_{\mathrm{CO}} \Rightarrow 1$ although a positive electrode charging leads to the structure depicted in Fig 9 on both Pt(111) and $\mathrm{Rh}(111)$ The interactions involved in the structure illustrated in Fig 4 1(c) favour the desorption of $\mathrm{CO}$

A similar analysis can be extended to $\mathrm{Rh}(100)$ and Pt(100) surfaces At low $\theta_{\mathrm{CO}}$ the $\mathrm{CO}$ adsorbate on either $\mathrm{Rh}(100)$ or $\mathrm{Pt}(100)$ constitutes $c(2 \times 2)$ LEED patterns through the occupancy of bi-coordinated sites (Fig 10(a)) When a positive potential is applied to these structures, they change to one of those illustrated in Figs 10(b)-10(d) involving configurations such as those depicted in Figs 51 and 52 As $\theta_{\mathrm{CO}}$ is increased, the linearly coordinated $\mathrm{CO}$ adsorbate on both $\mathrm{Rh}(100)$

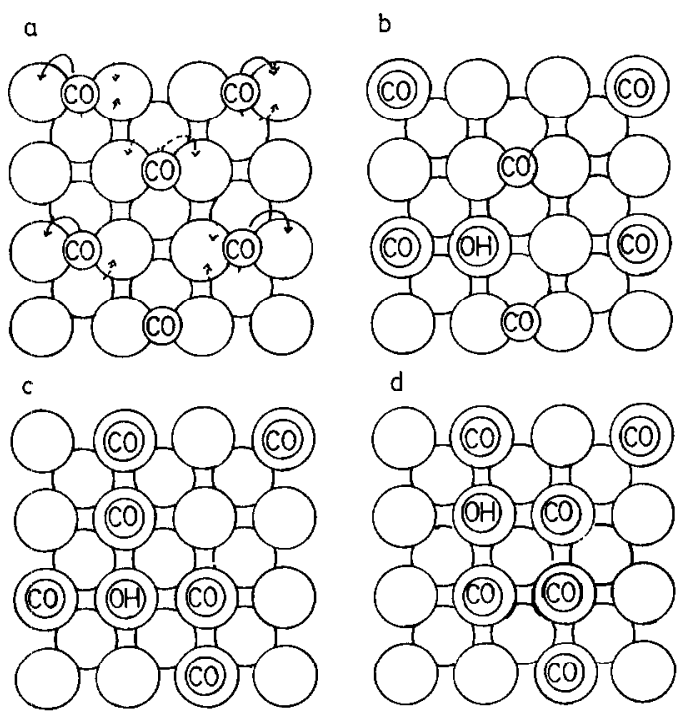

Fig 10 Possible structures of adsorbed CO on Me(100) at $\theta_{\mathrm{CO}}=05$ (a) $c(2 \times 2)$ LEED pattern derived for the uncharged metal, (b, c, d) possible structure modifications resulting by shiftıng the potential positively The $\mathrm{OH}$ adsorption site is also included 

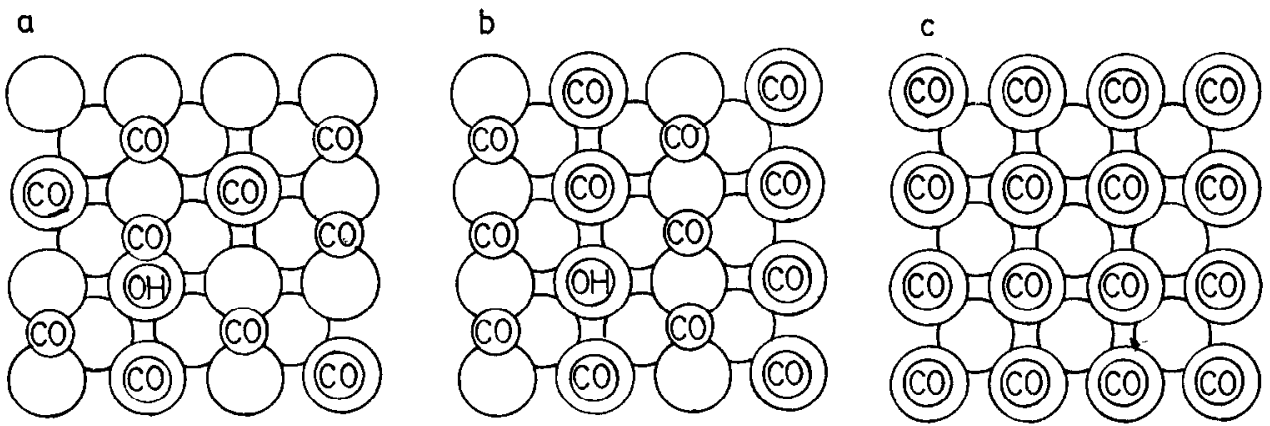

Fig 11 Structures corresponding to relatively high CO surface coverages on $\mathrm{Me}(100)$ (a) uncharged surface, $\mathrm{Me}=\mathrm{Pt}, \theta=065, c(2 \times 2) \mathrm{LEED}$ pattern, (b) uncharged surface, $\theta=075, \mathrm{Me}=\mathrm{Rh},(2 \times 1)$ LEED pattern, (c) possible structure resulting from increasing $\theta_{\mathrm{CO}}$ and shifting the potential positively $\mathrm{A}$ local vacancy is required for $\mathrm{OH}$ adsorption

and $\mathrm{Pt}(100)$ leads to $c(2 \times 1)$ and $c(4 \times 2)$ structures, respectively (Fig 11) Accordingly, under a posilive potential and with $\theta_{\mathrm{CO}}=1$, only the interactions resulting for the surface structure depicted in Fig 5 1(c) contribute to the rupture of the adsorbates from both metals

The binding energy levels of the different coadsorbate structures illustrated in Figs 4 1(a)-4 1(c), 4 2(a), $43(\mathrm{a}), 5$ 1(a) -51 (c), 52 (a) and 52 (b) change continuously as the applied potential is progressively increased from $00 \mathrm{~V}$ to $10 \mathrm{~V}$, so that these structures become less stable than those shown in Figs 41 (d)-41(f), $42(\mathrm{~b}), 43(\mathrm{~b}), 51(\mathrm{~d})-51(\mathrm{f}), 52(\mathrm{c})$ and $52(\mathrm{~d})$ The values of BE for adsorbate ensembles for which $n=m=1$ plotted against the applied potential (Fig 12) indicate that the $[\mathrm{Me}]_{N}(\mathrm{CO})(\mathrm{OH})$ ensemble is the most stable at low potentials, in contrast with the $[\mathrm{Me}](\mathrm{CO})_{2}$ ensemble From these results, it is possible to define the stability inversion potential (SIP) of each ensemble as

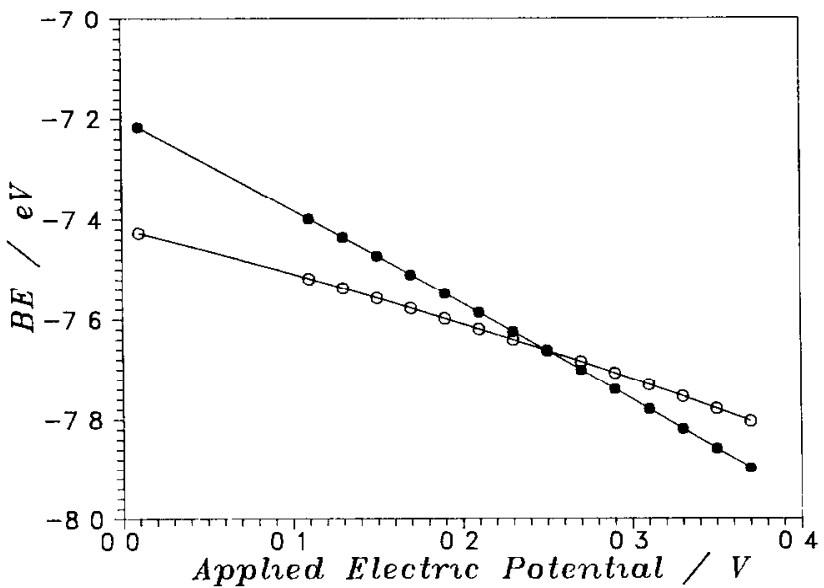

Fig 12 Binding energy of adsorbed $(\mathrm{CO})(\mathrm{OH})(\mathrm{O})$ and of adsorbed $(\mathrm{CO})_{2}(\bullet)$ ensembles on $[\mathrm{Pt}(111)\rfloor_{22}$ as a function of the applied electric potential The crossing point of the straight lines determınes the SIP the potential value at which the energy range of the stable structure is exceeded When this occurs the ensemble can change into another form by losing $\mathrm{CO}_{2}$, according to a process such as

$$
\begin{aligned}
& {[\mathrm{Me}]_{N}(\mathrm{CO})_{n}(\mathrm{OH})+2(\mathrm{CO})} \\
& \quad \Rightarrow[\mathrm{Me}]_{N}(\mathrm{CO})_{n+1}+\mathrm{H}^{+}+\mathrm{CO}_{2}+\mathrm{e}^{-}
\end{aligned}
$$

where, as discussed previously, the extra $\mathrm{CO}$ molecules in eqn (6) are associated with the adsorbate ensemble or islands in the framework of the nucleation and growth model It should be noted that results from experıments involving ${ }^{12} \mathrm{CO}+{ }^{13} \mathrm{CO}$ mixtures demonstrate that $\mathrm{CO}$ electrosorbed on $\mathrm{Pt}$ or $\mathrm{Rh}$ has the ability to undergo a rapid exchange with solution phase CO [46] These results are consistent with the presence of adsorbate $\mathrm{CO}$ structures on the surface

On the assumption that reaction (6) represents the electro-oxidation of the adsorbate, the SIP values related to the different adsorbate configurations can be related to the potentials of the various voltammetric anodic peaks reported for the electro-oxidation of $\mathrm{CO}$ adsorbed on $\mathrm{Pt}(100), \mathrm{Pt}(111), \mathrm{Rh}(100)$ and $\mathrm{Rh}(111)$ in aqueous acid solutions, provided that the comparison is made at a constant potential sweep $v$ 'This implies that the various possible reactions involve the same irreversible behaviour as expressed, for instance, through a constant peak potential dependence on $v$ for all reactions $[7,8]$ Accordingly, the theoretical electro-oxidation potential (EOP) corresponding to the voltammetric peaks can be calculated from the SIP values as follows

$\mathrm{EOP}=\mathrm{SIP} / g$

where in this case $g$, which has been already defined in Section 2, is also a function of the potential sweep rate

The experimental and theoretical EOP values and the values of $g$ employed for the different Pt crystal faces at $v=10 \mathrm{~V} \mathrm{~s}^{-1}$ are given in Table 2 A qualitative description of the multiplicity of anodic voltam- 
metric peaks for CO adsorbates at low $\theta_{\mathrm{CO}}$ on both $\mathrm{Pt}(111)$ and $\mathrm{Pt}(100)$ can be proposed as follows

The voltammetric anodic current peak at $081 \mathrm{~V}$ on Pt(111) can be assigned to the rupture of adsorbate structures produced at low values of $\theta_{\mathrm{CO}}$ (Fig 41 (a)) As the value of $\theta_{\mathrm{CO}}$ on $[\mathrm{Pt}(111)]_{22}$ increases, the voltammetric peak at $096 \mathrm{~V}$ resultıng from the rupture of the $(\mathrm{CO})_{2}(\mathrm{OH})$ ensemble (Fig 4 1(b)) is observed Subsequently, the peak at $110 \mathrm{~V}$ can be assigned to the rupture of the $(\mathrm{CO})_{3}(\mathrm{OH})$ ensemble $(\mathrm{Fig} 41(\mathrm{c}))$ Finally, bridge-bonded (CO)- $(\mathrm{OH})$ interactions (Figs $42(\mathrm{a})$ and $42(\mathrm{~b}))$ give rise to a peak at $12 \mathrm{~V}$, which, however, overlaps the oxygen evolution reaction (OER) potential region

The preceding analysis can be extended to $[\mathrm{Pt}(100)]_{25}$ for $\theta_{\mathrm{CO}} \rightarrow 1$ In this case the peak at $108 \mathrm{~V}$ can be related to the rupture of the $(\mathrm{CO})_{3}(\mathrm{OH})$ ensembles (Fig 5 1(d)) Different ensembles can be formed for intermediate values of $\theta_{\mathrm{CO}}$ under a positive potential (Figs 51(b) and 51(c)), and their rupture can be related to peaks found at $083 \mathrm{~V}$ and $093 \mathrm{~V}$ Furthermore, the adsorbate structures on $[\mathrm{Pt}(100)]_{25}$ associated with low values of $\theta_{\mathrm{CO}}$ (Figs 51 (a) and $52(\mathrm{a})$ ) become unstable only when the applied potential exceeds $03 \mathrm{~V}$ In this case the residual bridge-bonded CO (Fig 52 (b)) becomes sufficiently stable up to potentials near the OER threshold potential

Following the same type of analysis for $\mathrm{Rh}(111)$, the voltammetric peak at $095 \mathrm{~V}$ can be assigned to the rupture of the $(\mathrm{CO})_{3}(\mathrm{OH})$ ensemble (Fig 41 (c)) for any value of $\theta_{\mathrm{CO}}$ Nevertheless, for positive charging and low values of $\theta_{\mathrm{CO}}$ the rupture of the linearly bonded $(\mathrm{CO})_{2}(\mathrm{OH})$ ensemble (Fig 4 1(b)) would give rise to the anodic current peak at $075 \mathrm{~V}$ In this case, the $\mathrm{CO} \mathrm{OH}$ interaction (Fig 4 1(a)) prevaling at low values of $\theta_{\mathrm{CO}}$ would produce an electro-oxıdation peak at $047 \mathrm{~V}$ which has not been observed

The $\mathrm{CO} \mathrm{OH}$ adsorbed ensemble on $\mathrm{Rh}(100)$ becomes unstable at potentials more positive than those calculated for $\mathrm{Rh}(111)$ However, the peak potential related to the rupture of [linearly bonded $(\mathrm{CO})_{2}-(\mathrm{OH})$ ] and [lınearly bonded $(\mathrm{CO})$-bridge-bonded $(\mathrm{CO})-(\mathrm{OH})$ ] ensembles on $\mathrm{Rh}(100)$ (Figs 51 (b) and 52 (b)) overlaps that expected from the $(\mathrm{CO})_{3}(\mathrm{OH})$ ensemble on $\mathrm{Rh}(111)$ The same result is obtained for the $(\mathrm{CO})(\mathrm{OH})$ ensemble on $\mathrm{Rh}(100)$ (Fig $51(\mathrm{~d})$ ) and for the $(\mathrm{CO})_{2}(\mathrm{OH})$ ensemble on $\mathrm{Rh}(111)$ Accordingly, the higher stability of the $(\mathrm{CO})_{3}(\mathrm{OH})$ ensembles on $\mathrm{Rh}(100)$ furnishes no extra voltammetric peak Therefore these results explain why $\mathrm{CO}$ adsorbates on polycrystalline $\mathrm{Rh}$ exhibit an apparent single electro-oxidation current peak

It should be noted that the appearance of the anodic peaks at $075 \mathrm{~V}$ in acid solution $\left(1 \mathrm{M} \mathrm{HClO}_{4}, 05\right.$
$\left.\mathrm{M} \mathrm{H}_{2} \mathrm{SO}_{4}\right)$ and at $095 \mathrm{~V}$ in neutral solution $(02 \mathrm{M}$ $\mathrm{K}_{2} \mathrm{SO}_{4}$ ), which have been ascribed to $\mathrm{CO}$ electrooxidation from polycrystallıne $\mathrm{Rh}$, is consistent with the appearance of two peaks for $\mathrm{Rh}(100)$ in $01 \mathrm{M}$ $\mathrm{HClO}_{4}$ In addition, a single anodic peak at $095 \mathrm{~V}$ has also been found for $\mathrm{Rh}$ in $1 \mathrm{M} \mathrm{HClO}_{4}$ when $\theta_{\mathrm{CO}} \rightarrow 1$ $[18,19]$, with a shoulder at $075 \mathrm{~V}$

Since $\mathrm{CO}$ cannot displace completely the $\mathrm{H}$ adatoms from the $\mathrm{Rh}$ surface, either the fourth adsorption site on $\mathrm{Rh}(111)$ (Fig 4 1(d)) or both the third and fourth adsorption sites on $\mathrm{Rh}(100)$ (Figs 51 (c) and 51 (d) are likely to be occupied by $\mathrm{H}$ atoms which influence the electro-oxidation characteristics of the $\mathrm{CO}$ adsorbate ensembles for low $\theta_{\mathrm{CO}}$ Accordingly, depending on the $\mathrm{CO}$ adsorptıon tıme, either voltammetric peaks at 095 $\mathrm{V}$ and $075 \mathrm{~V}$ or a single peak at $075 \mathrm{~V}$ can be observed in acid

From the preceding analysis based upon the shift of the $\mathrm{CO}$ adsorbate electro-oxıdation peaks to lower potential values, it can be concluded that the occupation of $\mathrm{Rh}$ sites by $\mathrm{H}$ adatoms would preclude cooperative interactions involving the highest number of nearest-neighbour adsorbed $\mathrm{CO}$ molecules on the Rh surface

\section{Molecular orbital interpretation}

Cooperative interactions resulting from coadsorbed $\mathrm{CO}$ and $\mathrm{OH}$ species should emerge from molecular orbital interactions between these species and the metal surface $[31,32,67]$ It should be noted that $\mathrm{H}_{2} \mathrm{O}$ electrodecomposition yielding adsorbed $\mathrm{OH}$ and $\mathrm{H}^{+}$ions on both $\mathrm{Rh}$ and $\mathrm{Pt}$ in acid solution begins at relatively low potentials at which the metal surfaces is already almost covered by linearly bonded $\mathrm{CO}$ adsorbates

As can be seen in Fig 13, the stabilization of $\mathrm{OH}$ orbitals through bonding interactions occurs in a simlla1 manner on both $[\mathrm{Me}]_{N}(\mathrm{CO})_{n}$ and $[\mathrm{Me}]_{N}$ substrates However, perturbative interactions involving $\mathrm{OH}$ and preadsorbed $\mathrm{CO}$ shift the energy of antıbonding $\mathrm{Me}(\mathrm{OH})$ orbital levels up, this explains why $\mathrm{OH}$ becomes more strongly bound to the metal as the number $n$ of $\mathrm{CO}$ molecules in the adsorbate ensemble increases Thus, for a given applied potential and metal surface structure (Fig 13), the adsorption energy for $\mathrm{OH}$ on $[\mathrm{Me}]_{N},[\mathrm{Me}]_{N}(\mathrm{CO}),[\mathrm{Me}]_{N}(\mathrm{CO})_{2}$ and $[\mathrm{Me}]_{N}(\mathrm{CO})_{3}$ increases the stability of the coadsorbate ensemble produced by the less effective $\mathrm{OH}$ antıbonding interaction

However, the Fermı energy level of the metal surface decreases with positive potentials (positive charging) Accordingly, the stability of coadsorbate ensembles decreases on increasing the strength of the antibonding interactions The greater the value of $\theta_{\mathrm{CO}}$, the 
higher is the electric potential required for the adsorbate electro-oxidative desorption, assuming that it occurs according to reaction (6), when the surface site, which is fully occupied by $\mathrm{CO}$ molecules, becomes more stable
The present calculations also show that, as expected, the interactions between constituents within the proper adsorbate ensemble, either $[\mathrm{Me}]_{N}(\mathrm{CO})(\mathrm{OH})$ or $[\mathrm{Me}]_{N}(\mathrm{CO})(\mathrm{CO})$, depend on the distance between the constituents As the interactions between adjacent
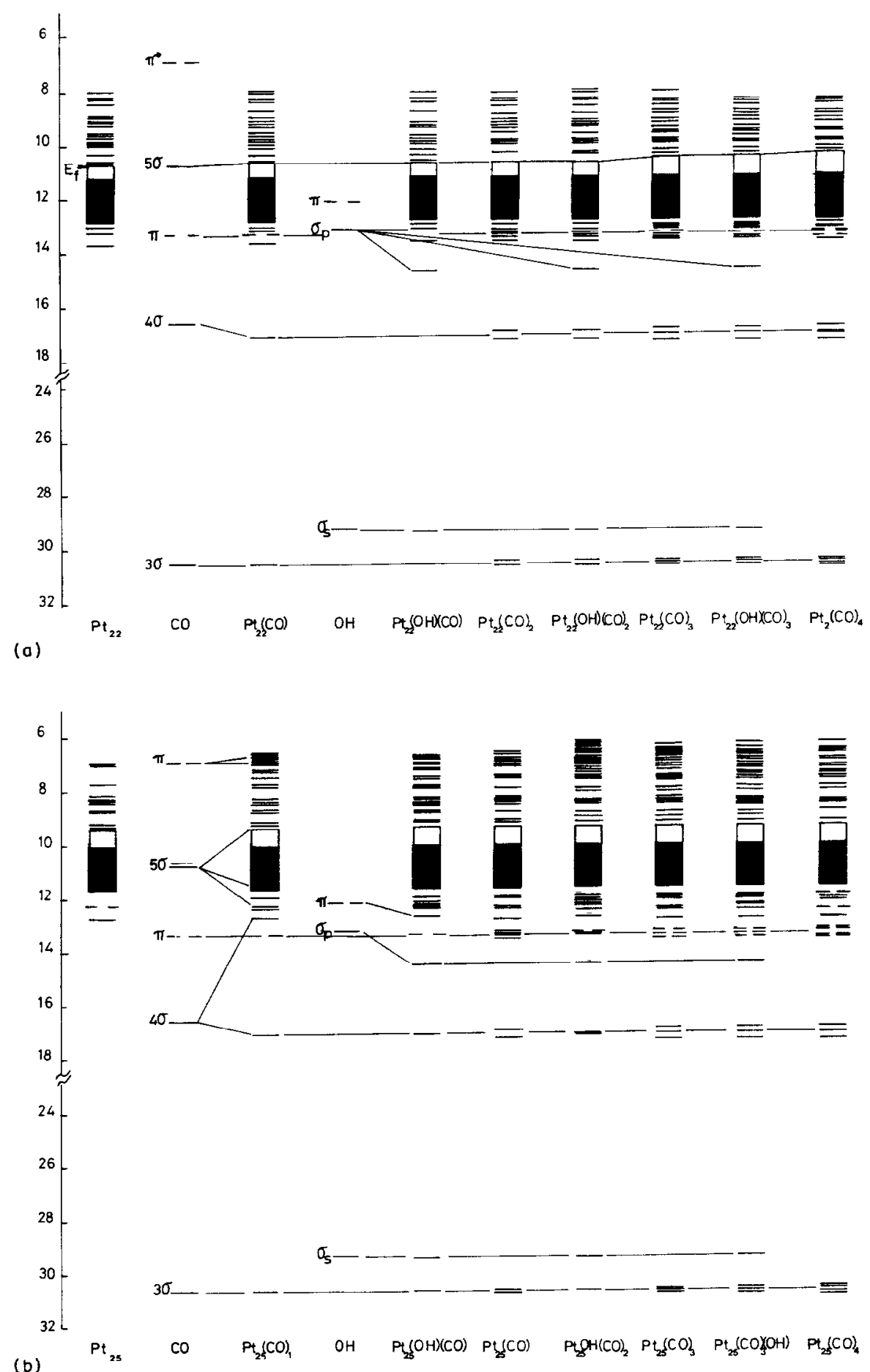

Fig 13 Molecular orbital correlation diagrams for the adsorption and coadsorption of $(\mathrm{CO})_{n}(0 \leq n \leq 4)$ and $(\mathrm{OH})$ on $[\mathrm{Me}]_{N}(\mathrm{a})[\mathrm{Me}]_{N}=$ $[\operatorname{Pt}(111)]_{22},(\mathrm{~b})[\mathrm{Me}]_{N}=[\mathrm{Pt}(100)]_{25},(\mathrm{c})[\mathrm{Me}]_{N}=[\mathrm{Rh}(111)]_{22}$, (d) $[\mathrm{Me}]_{N}=[\mathrm{Rh}(100)]_{25}$ 
$\mathrm{CO}$ adsorbates are stronger than those for non-adjacent species, the potential required to electro-oxıdıze the ensemble shown in Fig 51(c) is greater than that required for the electro-oxidation of the ensemble shown in Fig 5 1(b)

However, the dependence of the perturbative inter-

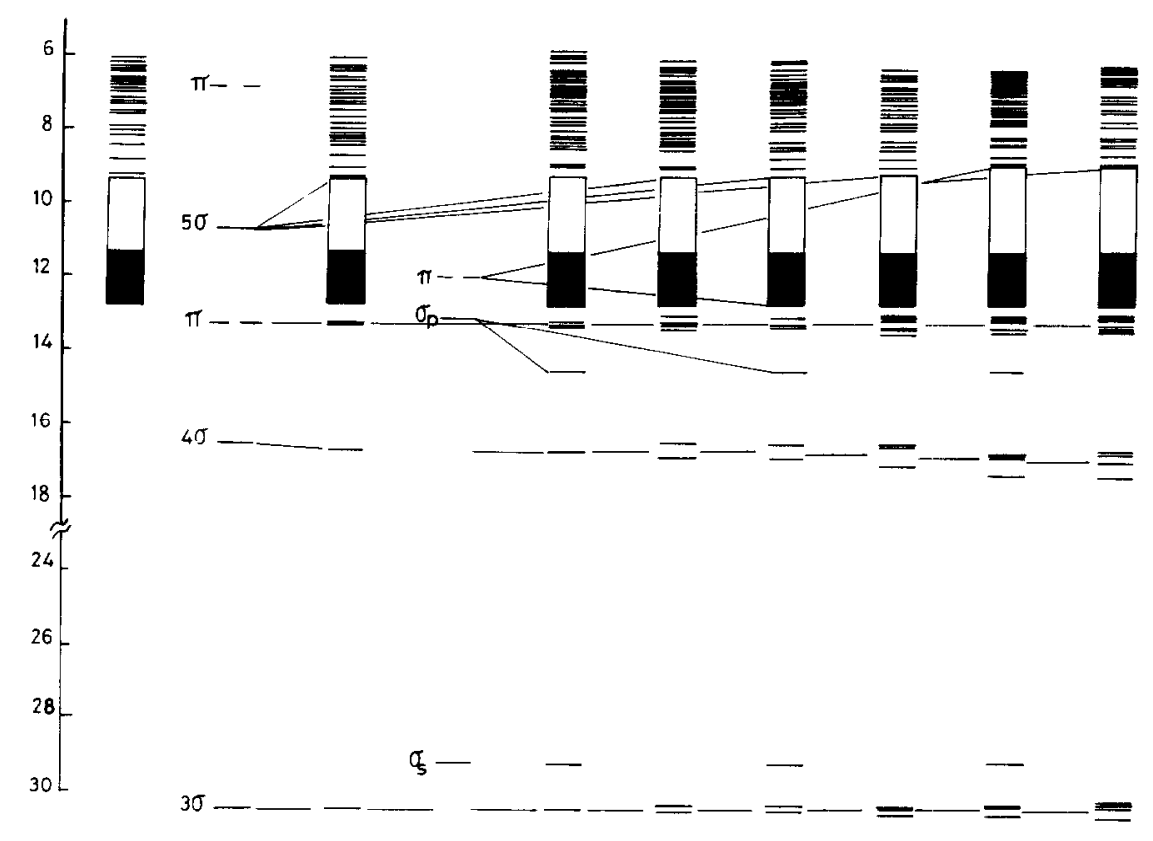

(c)

$\mathrm{Rh}_{22} \quad \mathrm{CO} \quad \mathrm{Rh}(\mathrm{CO}) \quad \mathrm{OH} \quad \mathrm{RhOHCO}_{22} \mathrm{Rh}_{22}(\mathrm{CO})_{2} \quad \mathrm{Rh}_{22} \mathrm{CO}_{2} \mathrm{OH} \quad \mathrm{Rh}_{22}(\mathrm{CO})_{3} \quad \mathrm{Rh}_{22}(\mathrm{CO})_{3} \mathrm{OH} \quad \mathrm{Rh}_{22}(\mathrm{CO})_{4}$

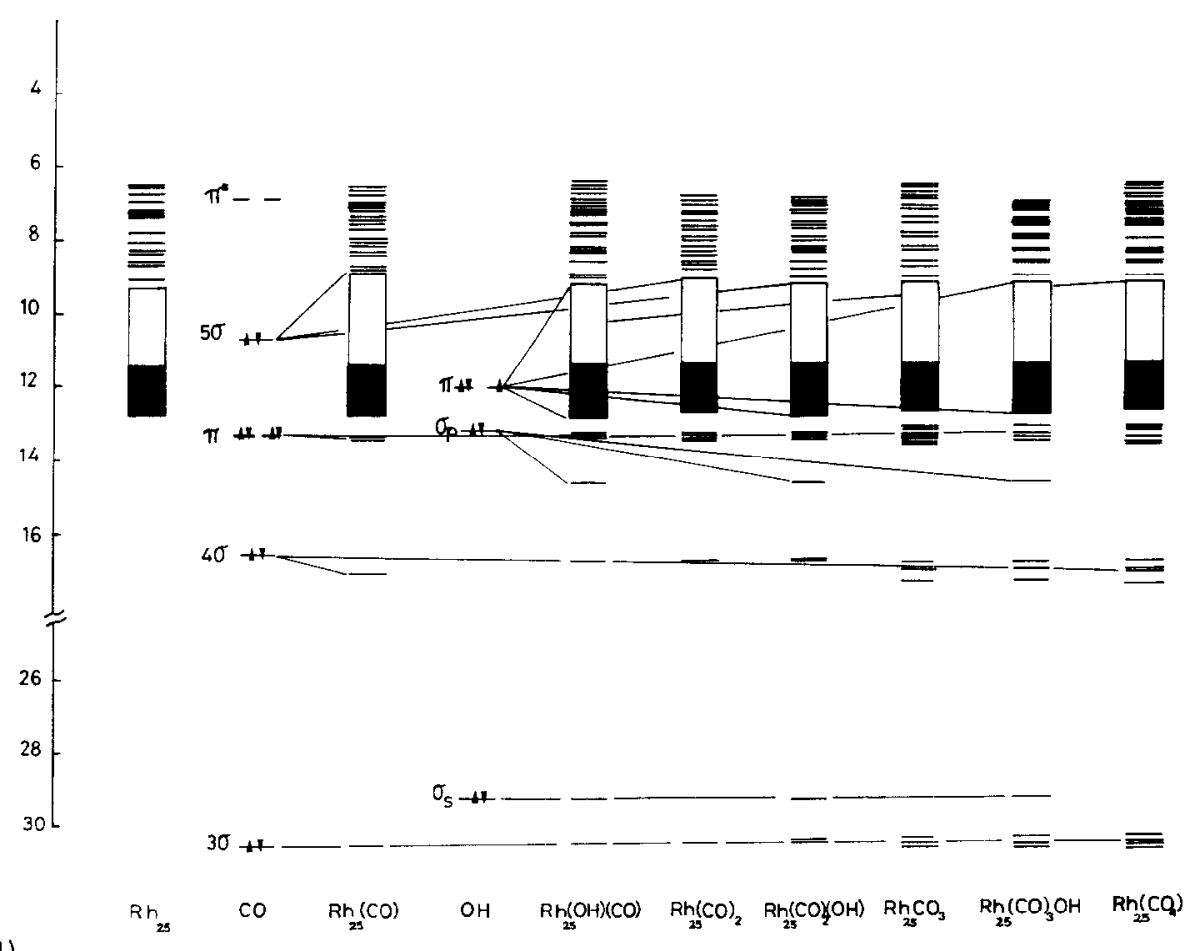

Fig 13 (contınued) 
actions on the distance between the ensemble constituents can explain immediately the surprisingly different electro-oxidation potentials of bridge-bonded and linearly bonded $\mathrm{CO}$ on $\mathrm{Me}(100)$ and $\mathrm{Me}(111)$ The perturbative interaction energies resulting for either $[\mathrm{Me}]_{N}$ (bridge-bonded $\left.\mathrm{CO}\right)(\mathrm{OH})$ or $[\mathrm{Me}]_{N}$ (linearly bonded $\mathrm{CO})(\mathrm{OH})$ ) on $\mathrm{Pt}(111)$ and $\mathrm{Rh}(111)$ respectively (Figs 42 and 43 ) generate extremely stable ensembles, so that the corresponding electro-oxidation potentials may fall in the potential range where $\mathrm{O}$ adatoms rather than $\mathrm{OH}$ adsorbed species are formed on both $\mathrm{Pt}$ and Rh Accordingly, it seems more reasonable to assign the voltammetric peak at $111 \mathrm{~V}$ to a surface oxıdative adsorbate process involving $\mathrm{O}$ adatoms and (CO) adsorbates instead of assigning it to (bridge-bonded $\mathrm{CO})(\mathrm{OH})$ adsorbate

\section{Acknowledgement}

The present work was supported by the Consejo Nacional de Investıgaciones Científicas y Técnicas of Argentına

\section{References}

1 B Beden, A Bewick, $\mathrm{K}$ Kunımatsu and C Lamy, J Electroanal Chem , 142 (1982) 345

$2 \mathrm{~J}$ Léger, B Beden, C Lamy and S Bilmes, J Electroanal Chem , 170 (1984) 305

3 F Kitamura, M Takahashı and M Ito, J Phys Chem, 92 (1988) 3320

4 L Leung, A Wieckowskı and M Weaver, I Phys Chem, 92 (1988) 6985

5 S G Sun, J Clavilier and A Bewıck, J Electroanal Chem, 240 (1988) 147

6 R Parsons and T VanderNoot, J Electroanal Chem, 257 (1988) 9

7 F Hahn, B Beden and C Lamy, J Electroanal Chem, 258 (1989) 115

$8 \mathrm{Z}$ Cataldı, R O Lezna, M C. Gıordano and A J Arvia, J Electroanal Chem, 261 (1988) 61

$9 \mathrm{~W}$ Bold and M Breıter, Electrochım Acta, 5 (1961) 145

$10 \mathrm{D} E$ Iienhower, H B Urbach and J H Harrison, J Electrochem Soc , 117 (1970) 1500

11 F Wagner and T Moylan, Surf Scı, 206 (1988) 187

$12 \mathrm{~F}$ Wagner and T Moylan, Surf Scı , 182 (1987) 125

13 F Wagner and T Moylan, Surf Scı, 195 (1988) 403

$14 \mathrm{~J}$ Clavilıer, A Fernández Vega, J M Felıú and A Aldaz, J Electroanal Chem, 263 (1989) 217

15 M Shibata, N Furuya, M Watanabe and S Motoo, J Electroanal Chem, 263 (1989) 97

16 M Shibata and N Furuya, J Electroanal Chem, 269 (1989) 217

17 N Furuya and M Shıbata, J Electroanal Chem, 266 (1989) 461

$18 \mathrm{~S}$ Bilmes, M C Giordano and A J Arvia, J Electroanal Chem, 215 (1987) 183

19 S Bilmes, MC Giordano and A J Arvia, Can J Chem, 66 (1988) 2259

20 S Bilmes, N R de Tacconı and A J Arvia, J Electroanal Chem, 164 (1984) 129
$21 \mathrm{~K}$ Kunimatsu, R O Lezna and M Enyo, J Electroanal Chem, 258 (1989) 115

$22 \mathrm{H}$ Stemiger, S Leeward and H Ibach, Surf Scı, 123 (1982) 264

23 L K Verhey, L Lux, A Anton, B Poetsemand and G Comsa, Surf Sc1, 182 (1987) 390

24 A M Lahee, J P Trennies and C Woll, Surf Sc1, 177(1986) 371

$25 \mathrm{~J}$ Biberian and M Van Hove, Surf Scl, 118 (1982) 443

$26 \mathrm{~J}$ Biberian and M Van Hove, Surf Sc1, 138 (1984) 361

27 Shın-ıchı Ishı, Y Ohno and B Viswanathan, Surf Scı, 161 (1985) 349

28 S C Chang, L W H Leving and M J Weaver, J Phys Chem, 93 (1989) 5341

29 S C Chang and M J Weaver, J Electroanal Chem, 285 (1990) 263

30 K Kunımatsu, J Phys Chem, 88 (1984) 2197

31 G L Estıú, S A Maluendes, E A Castro and A J Arvia, J Electroanal Chem, 283 (1990) 303

32 P Paredes Olıvera, G L Estıú, E A Castro and A J Arvia, J Mol Struct (THEOCHEM), 210 (1990) 379

33 S A Bilmes and A J Arvia, J Electroanal Chem, 361 (1993) 159

34 J A Caram and C Guttérrez, J Electroanal Chem, 307 (1991) 99

35 J A Caram and C Gutiérrez, J Electroanal Chem, 305 (1991) 259

36 L H Leung and M J Weaver, J Phys Chem, 93 (1989) 7218

37 L W H Leung, S C Chang and M J Weaver, J Chem Phys, 90 (1989) 7426

38 L H Leung and M J Weaver, J Am Chem Soc, 109 (1987) 5113

39 G L Estıú and M C Zerner, Int J Quantum Chem, 26 (1992) 587

40 G L Estıú and M C Zerner, J Phys Chem, submitted

41 A Goursot, I Papal and D R Salahub, J Am Chem Soc, in press

42 A St Amant, Ph D Thesis, Université de Montreal, 1991

43 P S Bagus, CN Nelın and CW Bauschlıcher, Phys Rev B, 28 (1983) 5423

44 C W Bauschlıcher, P S Bagus, C N Nelın and B Roos, J Chem Phys, 85 (1986) 354

45 L A Barnes and CW Bauschlicher, J Chem Phys, 91 (1989) 314

46 S C Chang, J D Roth and M J Weaver, Surf Scı, 244 (1991) 113

47 S C Chang and M J Weaver, Surf Sc1, 238 (1990) 142

48 S C Chang and M J Weaver, J Chem Phys, 92 (1990) 4582

49 S C Chang and M J Weaver, J Phys Chem, 94 (1990) 5095

50 S C Chang and M J Weaver, Surf Scl, 230 (1990) 222

51 B Love and J Lipkowskı, Am Chem Soc Symp Ser, 378 (1988) 489

52 A Anderson, R W Grimes and S Hong, J Phys Chem, 91 (1987) 4245

53 N Ray and A Anderson, Surf Scı, 125 (1983) 803

$54 \mathrm{E}$ Clementı and C Roettı, Atomic Data and Nuclear Data Tables, Vol 14, Academıc Press, New York, 1974

55 L W Anders, R Hansen and L Bartell, J Chem Phys, 59 (1973) 5277

56 W Lotz, J Opt Soc Am, 60 (1970) 206

$57 \mathrm{C}$ Moore, Atomic Energy Levels, NBC Circular 467, National Bureau of Standards, US Government Printıng Office, Washıngton, DC

58 L Pauling, The Nature of the Chemical Bond (3rd edn), Cornell University Press, Ithaca, NY, 1960

59 E Kotz, H Neff and K Muller, J Electroanal Chem, 215 (1986) 33 
60 D Kolb, D Rath, R Wille and W Hansen, Ber Bunsenges Phys Chem , 87 (1983) 1108

61 W Boek and D Kolb, Surf Sc1, 118 (1982) 613

62 L J Richter, T A Giermer and W Ho, Surf Sci 195 (1988) L182 63 G Pachionı and J Koutecky, J Phys Chem, 91 (1987) 2658

64 A Anderson and M Awad, J Am Chem Soc, 107 (1985) 7854
65 P Paredes Olivera, G L Estıú, E A Castro and A J Arvia, J Mol Struct (THEOCHEM), 210 (1990) 351

66 K Herman, P Bagus and C Nelın, Phys Rev B, 35 (1987) 9467

$67 \mathrm{P}$ Thiel, E Willıams, J Yates and W Weınberg, Surf Scı, 84 (1979) 54 